\title{
Perancangan dan Implementasi Multimedia Interaktif Berbasis Android pada Mata Pelajaran IPA di Sekolah Menengah Atas
}

\author{
Muhammad Ikhlas \\ Fakultas Ilmu Komputer, Universitas Putra Indonesia "YPTK” Padang \\ Email: mhdikhlas@upiyptk.ac.id
}

\begin{abstract}
Abstrak
Pengembangan media pembelajaran seperti multimedia interaktif memberikan variasi terhadap setiap proses pembelajaran. Materi pembelajaran yang disampaikan melalui visual media elektronik bertujuan untuk memberikan rasa yang berbeda pada siswa dibanding pembelajaran di kelas. Dalam perancangan sistem multimedia interaktif menggunakan alat bantu perancangan sistem yaitu UML (Unified Modelling Language) dan kemudian hasil rancangan diimplementasikan pada aplikasi Adode Flash CS6 berbasis Android, sehingga aplikasi nantinya dapat dijalankan pada platform Android. Aplikasi multimedia interaktif pada mata pelajaran biologi ini juga dilengkapi dengan menu evaluasi, sehingga setiap siswa yang telah selesai mempelajari materi yang tersaji di dalam aplikasi, dapat mengerjakan beberapa soal yang disediakan. Setelah menyelesaikan soal, siswa juga dapat mengetahui nilai dan jumlah jawaban yang benar dari soal tersebut. Sehingga dengan adanya evaluasi tersebut akan memberikan tolok ukur pada kemampuan siswa dalam belajar. Penelitian ini menggunakan metode penelitian dengan langkah-langkah yaitu penelitian pendahuluan, kajian teori, analisa dan perancangan sistem, implementasi sistem dan evaluasi.
\end{abstract}

Kata-kata kunci: Multimedia Interaktif, biologi, UML, Android

\section{Design and Implemention Interactive Multimedia Based on Android for Natural Science Subjects In Senior High Schools}

\author{
Muhammad Ikhlas \\ Faculty of Computer Science, Universitas Putra Indonesia "YPTK” Padang \\ Email: mhdikhlas@upiyptk.ac.id
}

\begin{abstract}
Development of instructional media such as interactive multimedia provides variations on each learning process. Learning material delivered through electronic visual media aims to give students a different feel than learning in the classroom. In designing interactive multimedia systems using a system design tool that is UML (Unified Modeling Language) and then the design results are implemented on the Androidbased Flash Adode CS6 application, so that later applications can be run on the Android platform. This interactive multimedia application on biology courses is also equipped with an evaluation menu, so that every student who has finished studying the material presented in the application, can do some of the questions provided. After completing the questions, students can also find out the value and number of correct answers of the questions. So that the evaluation will provide a benchmark on the ability of students to learn. This study uses a research method with steps, namely preliminary research, theoretical study, system analysis and design, system implementation and evaluation. $h$
\end{abstract}

Keywords: Interactive Multimedia, biology, UML, Android 


\section{PENDAHULUAN}

Keterbatasan sumber daya dan variasi belajar sekolah-sekolah di Indonesia masih menjadi perhatian khusus yang harus dipikirkan banyak orang, terutama dari kalangan intelektual. Konsep belajar yang terbilang masih konvensional membuat banyak siswa menjadi jenuh dan bosan dengan proses belajar mengajar (PBM) seperti itu. Rata-rata baik di perkotaan maupun di daerah dalam proses belajarnya masih menggunakan buku tulis, buku ajar (cetak), papan tulis dan lain sebagainya, salah satu diantaranya di SMA N 2 Pulau Punjung. Sehingga perlu adanya inovasi dan variasi belajar yang mengikuti perkembangan dunia, terutama perkembangan teknologi.

Perkembangan ilmu pengetahuan dan teknologi (IPTEK) memberikan tantangan tersendiri bagi lulusan ilmu pendidikan untuk menciptakan media pembelajaran yang dapat meningkatkan mutu pendidikan yang lebih baik. berkembangnya IPTEK mendorong guru untuk menghasilkan media pembelajaran berbasis komputer. Dengan kemajuan teknologi, memudahkan guru membuat media pembelajaran untuk mata pelajaran yang membutuhkan biaya tinggi (Muyaroah \& Fajartia, 2017).

Madcoms (dalam Apriyani, 2012:20) juga mengemukakan bahwa Adobe Flash CS6 adalah software yang baik digunakan untuk mendukung pembelajaran interaktif. Karena, media pembelajaran interaktif dengan aplikasi Adobe Flash CS6 dapat menggabungkan grafis, animasi, suara, serta memiliki kemampuan untuk melakukan interaksi dengan pengguna (Hidayah, Wahyuni, \& Ani, 2017).

Perpaduan antara teknologi dan visualisasi akan mengubah paradigma seseorang terutama siswa dalam belajar. Karena saat ini pelajar-pelajar di Indonesia tidak terlepas dari penggunaan teknologi, contohnya seperti mencari tugas dan informasi lainnya melalui smartphone atau ponsel pintar. Dengan adanya aplikasi berupa multimedia interaktif yang dibuat dengan menggunakan Adobe CS6 berbasis Android, akan membantu siswa maupun guru untuk menyampaikan materi pelajaran dengan variasi yang lain, sehingga siswa tidak lagi jenuh dengan metode pembelajaran yang ada saat ini.

Di dalam perancangannya, penulis menggunakan alat bantu perancangan sistem berupa pemodelan UML (Unified Modelling Language), dimana objek dari penelitian berdasarkan apa dan siapa pengguna sistem. Sehingga dengan adanya media pembelajaran ini dapat membantu guru dalam menyampaikan pesan dalam proses belajar mengajar agar tujuan dari pembelajaran 
dapat tercapai dengan maksimal, terutama dalam hal ini beruapa mata pelajaran biologi di kelas X, XI dan XII SMA N 2 Pulau Punjung.

\section{METODE}

Penelitian ini menggunakan metode penelitian atau kerangka kerja yang terstruktur agar proses penelitian menjadi terarah. Adapun kerangka kerja dari penelitian dapat dilihat pada Gambar 1 berikut.

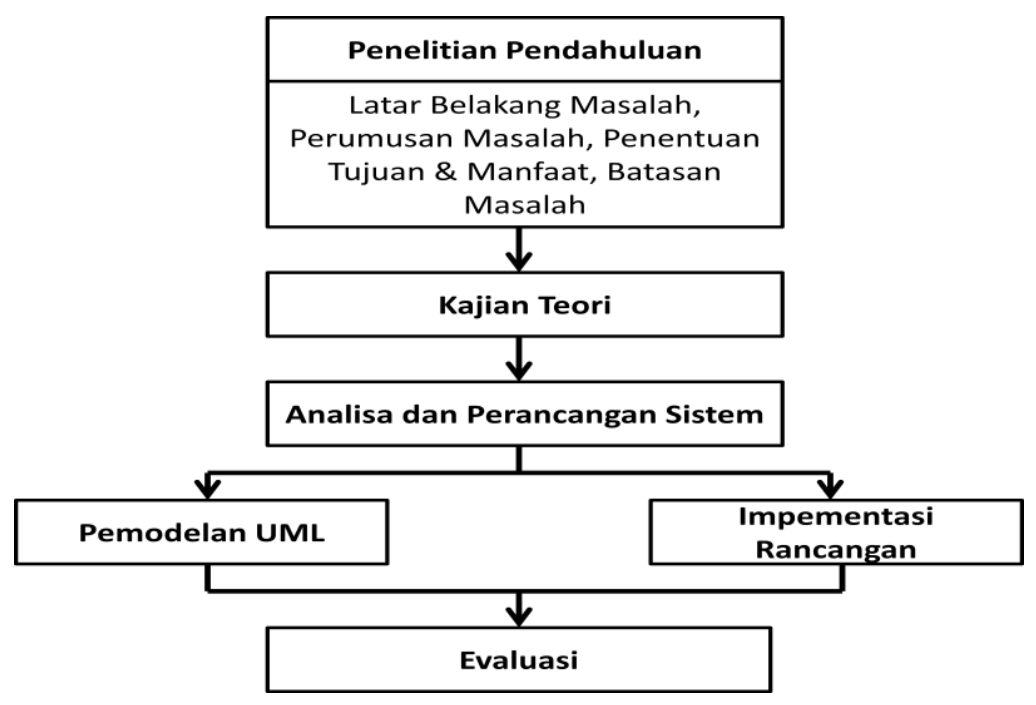

Gambar 1. Kerangka Kerja Penelitian

Penelitian Pendahulaun; kegiatan ini merupakan langkah awal dari penelitian yaitu mengumpulkan informasi dari objek yang diteliti kemudian membuatkan latar belakang masalah, tujuan dan manfaat penelitian serta batasan masalah apa saja yang akan dibahas didalam objek penelitian agar penelitian menjadi lebih terarah.

Kajian Teori; kegiatan ini bertujuan untuk menemukan referensi yang akan digunakan sebagai sumber teori yang relevan dengan penelitian.

Analisa dan Perancangan Sistem; pada tahap ini dilakukan analisa dan perancangan terhadap objek penelitian yaitu pada sistem pembelajaran yang ada di sekolah, pada tahapan ini analisa sistem dilakukan dengan menggunakan pemodelan UML dan implementasi dari rancangan menggunakan Adobe CS6 berbasis Android.

Evaluasi; tahap ini merupakan tahapan terakhir dari penelitian yaitu melakukan evaluasi 
terhadap hasil penelitian sebelum diterapkan pada sistem pembelajaran di sekolah. Dengan adanya evaluasi ini diharapkan hasil penelitian lebih optimal.

\section{HASIL DAN PEMBAHASAN}

Analisa sistem bertujuan untuk mengetahui permasalahan yang ada pada sistem pembelajaran yang lama, untuk kemudian dikembangkan menjadi sistem pembelajaran yang baru dengan menggunakan media pembelajaran. Pada tahap analisa dilakukan perancangan pada sistem, agar sistem yang akan dibangun menjadi terarah dan menghasilkan sistem yang sesuai dengan apa yang diharapkan. Pada analisa yang dilakukan, ditemukan bahwa kegiatan pembelajaran masih monoton, sehingga perlu adanya solusi terhadap sistem pembelajaran dengan dibuatkan sebuah aplikasi yang membantu guru dan siswa dalam proses belajar mengajar sehingga lebih bervariasi.

Pada tahap ini dilakukan perancangan terhadap sistem. Perancangan menggunakan alat bantu perancangan sistem berupa UML (Unified Modelling Language) yang terdiri atas beberapa diagram, diantaranya use case diagram, sequence diagram dan activity diagram.

\section{Use Case Diagram}

Salah satu diagram penting yang digunakan untuk mengilustrasikan kebutuhan (requirements) dari sistem adalah use case (UC) diagram, yang menjelaskan secara visual konteks dari interaksi antara aktor dengan sistem. Setiap use case menyatakan spesifikasi perilaku (fungsionalitas) dari sistem yang sedang dijelaskan yang memang dibutuhkan oleh aktor untuk memenuhi tujuannya (Kurniawan, 2018).

\section{Definisi Aktor}

Adapun aktor yang terlibat di dalam sistem dapat didefinisikan dengan satu aktor, yaitu $u$ ser.

Tabel 1. Definisi Aktor

\begin{tabular}{ll}
\hline Aktor & \multicolumn{2}{c}{ Keterangan } \\
\hline User & User merupakan orang yang memakai aplikasi media pembelajaran \\
& interaktif. User dapat melihat halaman utama dam memilih pilihan yang \\
& tersedia.
\end{tabular}

\section{Definisi Use Case}

Pada definisi use case ini menjelaskan tentang apa yang fungsional dari setiap unit kegiatan sistem. Setiap interaksi antara aktor dan sistem memiliki fungsi yang berbeda-beda. 
Dengan adanya definisi use case, maka dapat memberikan gambaran yang jelas terhadap aktifitas aktor.

Tabel 2. Defisnisi Use Case

\begin{tabular}{|c|c|c|}
\hline Use Case & Keterangan & Aktor \\
\hline Intro & Halaman pembuka saat aplikasi pertama dijalankan. & User \\
\hline Home & $\begin{array}{l}\text { Pada halaman ini merupakan halaman pembuka sebelum ke } \\
\text { halaman menu utama. }\end{array}$ & User \\
\hline Profil Sekolah & $\begin{array}{l}\text { Pada halaman ini user dapat melihat profil atau biodata } \\
\text { sekolah. }\end{array}$ & User \\
\hline Menu Utama & $\begin{array}{l}\text { Pada halaman ini user dapat memilih konten apa yang ingin } \\
\text { dilihat dalam menu tersebut. }\end{array}$ & User \\
\hline Profil & $\begin{array}{l}\text { Halaman ini berisi penjelasan profil atau biodata pembuat } \\
\text { aplikasi. }\end{array}$ & User \\
\hline Guru & $\begin{array}{l}\text { Berisi penjelasan profil atau biodata guru-guru pada mata } \\
\text { pelajaran biologi yang mengajar di sekolah. }\end{array}$ & User \\
\hline About & $\begin{array}{l}\text { Berisi tentang penjelasan aplikasi "Media Pembelajaran } \\
\text { Interaktif". }\end{array}$ & User \\
\hline Materi & $\begin{array}{l}\text { Berisi materi-materi mata pelajaran biologi dari kelas } \mathrm{X} \\
\text { sampai kelas XII. }\end{array}$ & User \\
\hline Evaluasi & $\begin{array}{l}\text { Pada halaman ini berisi evaluasi-evaluasi mata pelajaran } \\
\text { biologi dari kelas X sampai kelas XII untuk menguji } \\
\text { kemampuan siswa. }\end{array}$ & User \\
\hline Video & $\begin{array}{l}\text { Pada halaman ini berisi beberapa video tentang mata } \\
\text { pelajaran biologi dari kelas X sampai kelas XII. }\end{array}$ & User \\
\hline
\end{tabular}

\section{Diagram Use Case}

Setelah dilakukan analisa dengan mendefinisikan aktor dan use case, maka penulis dapat mengambarkan bagaimana use case diagram yang terjadi pada sistem media pembelaran ini. 


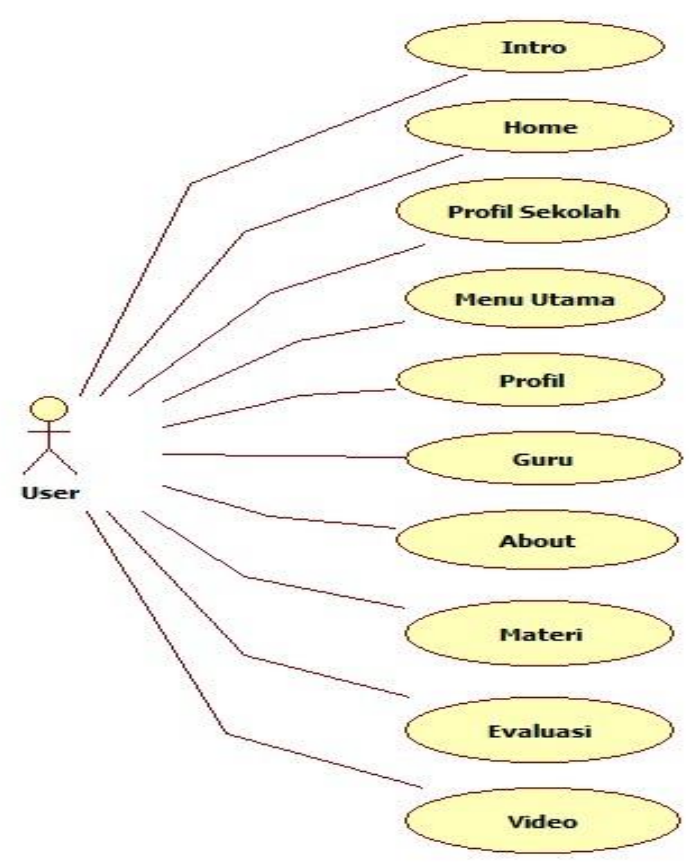

Gambar 2. Diagram Use Case

\section{Sequence Diagram}

Pada sequence diagram menjelaskan bagaimana entitas setiap objek pada sistem saling berinteraksi. Adapun sequence diagram utama pada aplikasi media pembelajaran ini adalah sebagai berikut :

\section{Sequence Diagram Materi}

Diagram ini menjelaskan tentang interaksi antara entitas sistem pada use case materi.

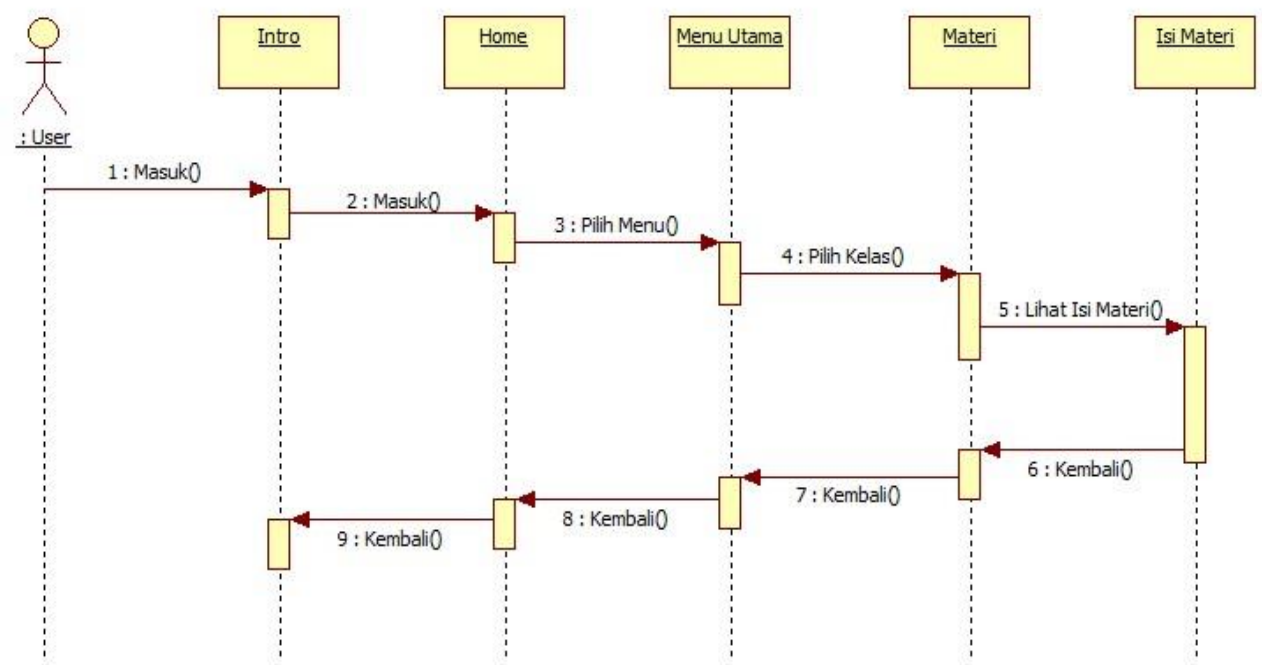

Gambar 3. Sequence Diagram Materi 
$w w w$.journal.univetbantara.ac.id/index.php/ijimm

\section{Sequence Diagram Evaluasi}

Diagram ini menjelaskan tentang interaksi antara entitas sistem pada use case evaluasi.

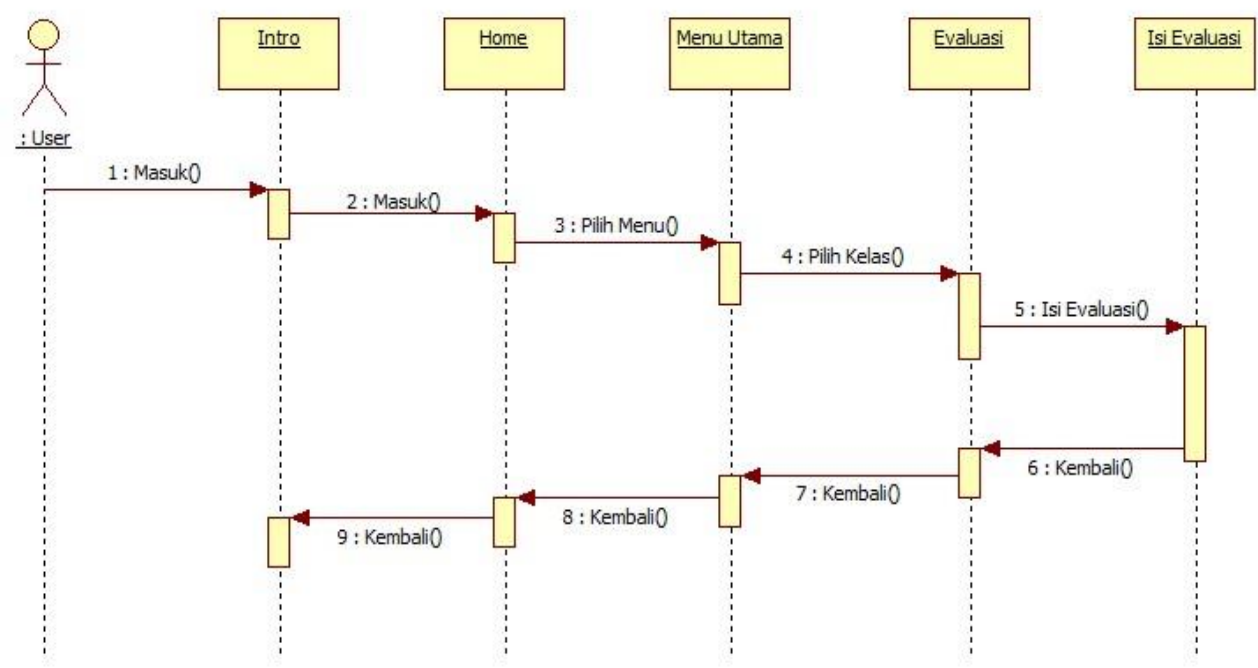

Gambar 4. Sequence Diagram Evaluasi

\section{Sequence Diagram Video}

Diagram ini menjelaskan tentang interaksi antara entitas sistem pada use case video.

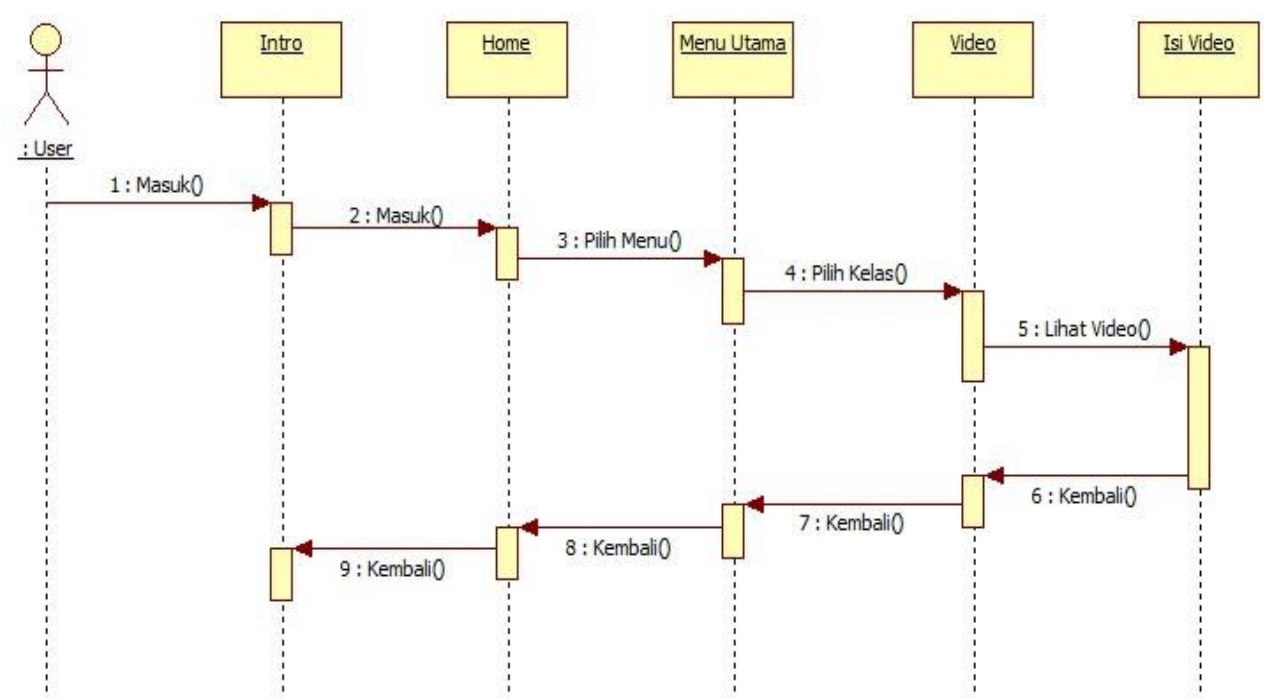

Gambar 5. Sequence Diagram Video 


\section{Activity Diagram}

Pada activity diagram atau diagram aktifitas, menjelaskan bagaimana aliran kerja pada sistem.

Dengan adanya diagram ini, dapat membantu user untuk mengetahui apa saja aktifitas atau alur kerja dari aplikasi media pembelajaran tersebut.

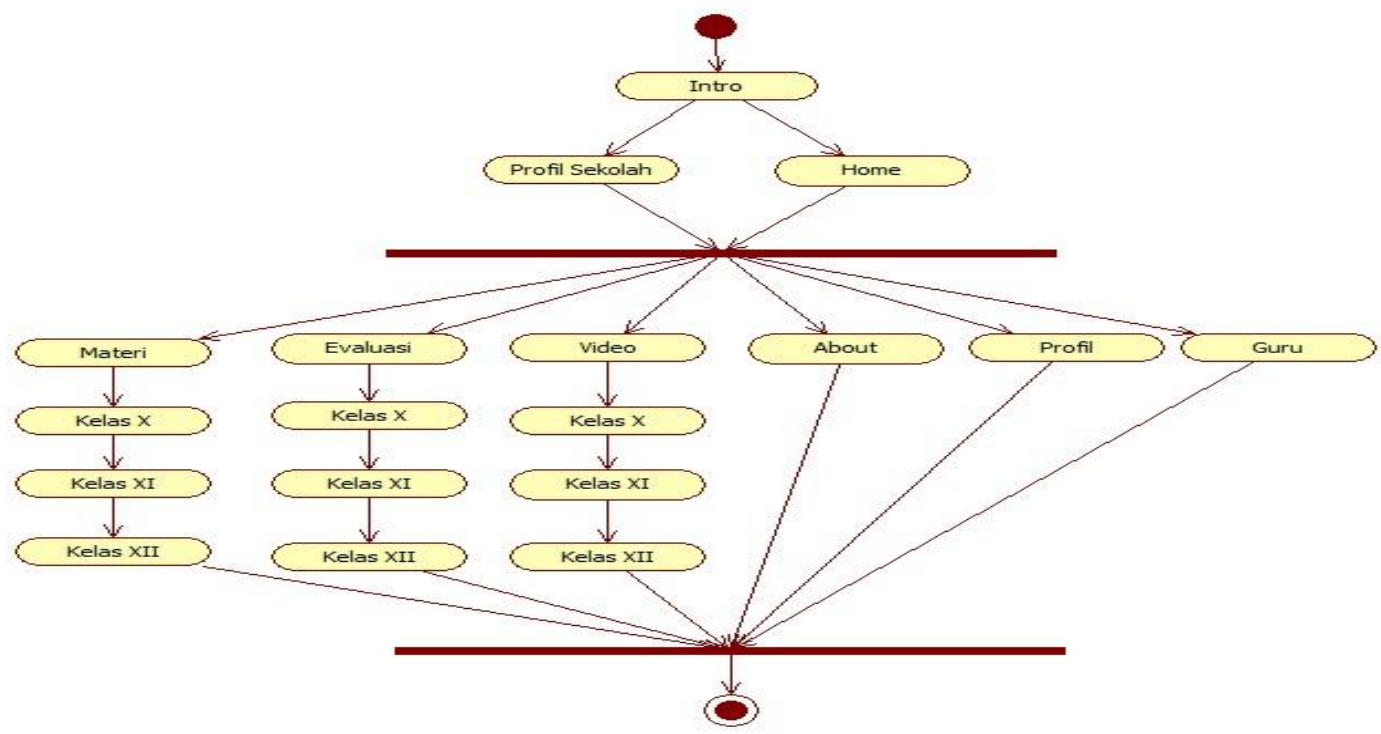

Gambar 6. Activity Diagram

\section{HASIL DAN PEMBAHASAN}

Setelah dilakukan analisa dan perancangan sistem, maka dilakukan implementasi terhadap rancangan sistem, dengan hasil rancangan sebagai berikut :

\section{Tampilan Menu Utama}

Menu utama merupakan, halaman utama dari aplikasi ketika dijalankan. Adapun menu yang tersedia adalah menu materi, evaluasi, video, dan tentang aplikasi. 


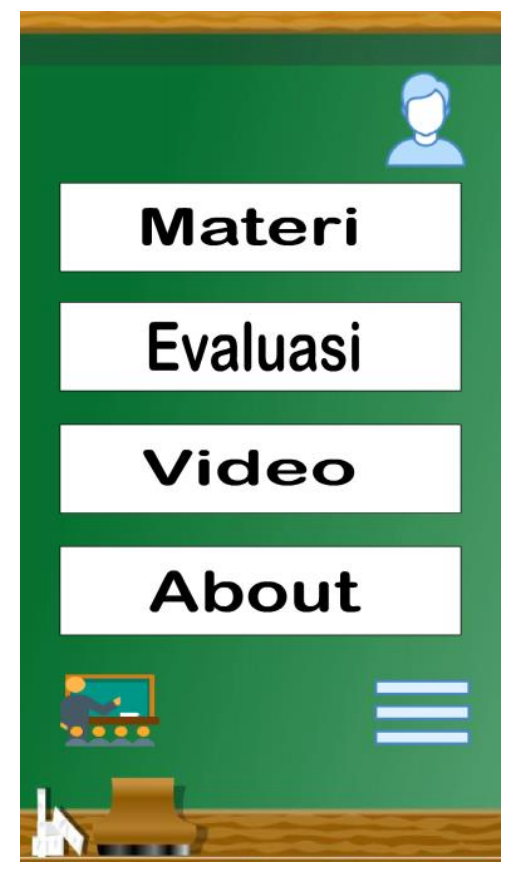

Gambar 7. Tampilan Menu Utama

Tampilan Menu Meteri

Menu materi merupakan materi pembelajaran yang ada pada setiap kelas, baik kelas X, XI, dan XII.

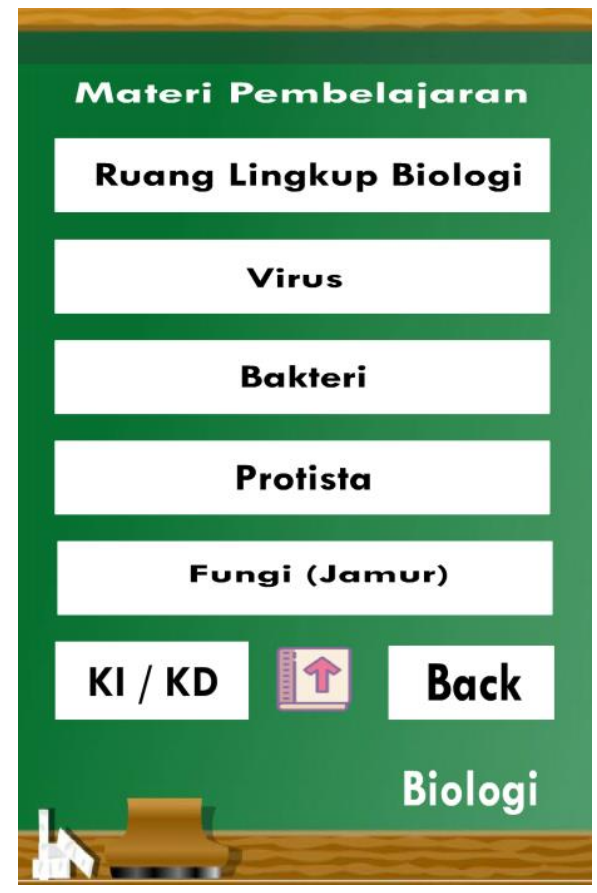

Gambar 8. Tampilan Menu Materi 


\section{Tampilan Menu Evaluasi}

Menu evaluasi merupakan menu yang bertujuan untuk menilai atau mengevaluasi materi yang telah disajikan di dalam sistem dan mengukur tingkat pemahaman siswa terhadap materi yang disajikan.

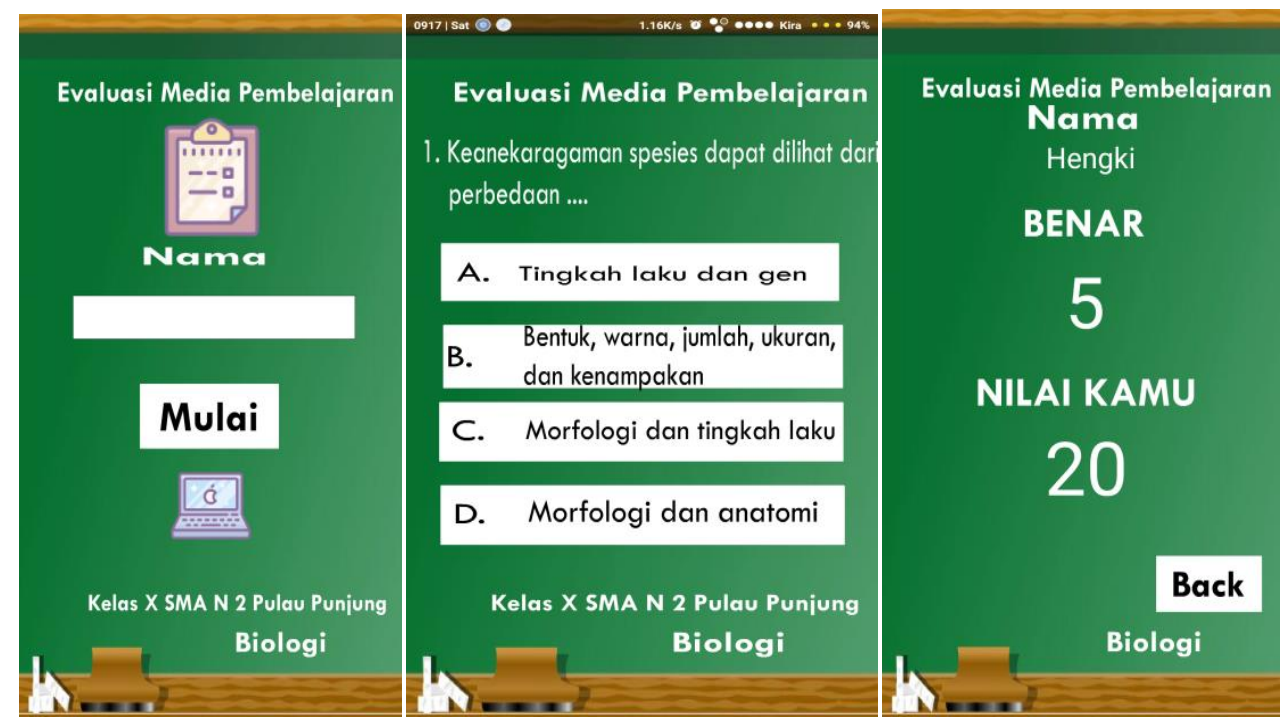

Gambar 9. Tampilan Menu Evaluasi

\section{SIMPULAN DAN SARAN}

Berdasarkan hasil dan evaluasi terhadap media pembelajaran ini, maka diperoleh kesimpulan bahwa dengan adanya media pembelajaran interaktif ini, proses belajar mengajar bagi siswa lebih bervariasi karena materi yang disajikan dalam bentuk visual yang dapat diakses oleh siswa dimanapun dan kapanpun sehingga tidak monoton dan membosankan seperti pembelajaran di kelas. Aplikasi ini dirancang untuk menggantikan metode konvensional yang sudah ada dengan metode animasi, sehingga dengan metode dan tampilan yang baru dan dapat membantu guru dalam proses belajar mengajar.

Adapun saran dari penulis untuk penelitian selanjutnya adalah aplikasi media pembelajaran dapat dikembangkan berbasis database, sehingga materi yang ada di dalam sistem dapat terus diperbaharui sesuai dengan perkembangan ilmu pengetahuan.

\section{DAFTAR REFERENSI}

Akil, I., Studi, P., Administrasi, M., \& Timur, J. (2016). REKAYASA PERANGKAT LUNAK DENGAN MODEL UNIFIED PROCESS STUDI KASUS : SISTEM INFORMASI JOURNAL, (1), 1-11.

A.S, Rosa dan M. Shalahuddin. 2014. Rekayasa Perangkat Lunak Terstruktur dan Berorientasi Objek. Bandung: Informatika Bandung. 
Hidayah, S., Wahyuni, S., \& Ani, H. M. A. (2017). PENGGUNAAN MEDIA PEMBELAJARAN INTERAKTIF DENGAN APLIKASI ADOBE FLASH CS6 UNTUK MENINGKATKAN MOTIVASI BELAJAR PADA KOMPETENSI DASAR MENGANALISIS PERAN, FUNGSI DAN MANFAAT PAJAK (Studi Kasus Siswa Kelas XI IPS 1 MAN 1 Jember Semester Genap Tahun Ajaran 2016. Jurnal Pendidikan Ekonomi: Jurnal Ilmiah Ilmu Pendidikan, Ilmu Ekonomi, Dan Ilmu Sosial, 11(1), 117-123.

Fatoni, A., \& Kuraesin, P. D. (2015). Rancang Bangun Multimedia Pembelajaran Interaktif Mata Pelajaran Ipa Terpadu Untuk Siswa Smpn 5 Kota Serang, 47-50.

Kurniawan, T. A. (2018). Pemodelan Use Case ( UML ): Evaluasi Terhadap beberapa Kesalahan dalam Praktik USE CASE ( UML ) MODELING : EVALUATION ON SOME PITFALLS IN PRACTICES, (March). https://doi.org/10.25126/jtiik.201851610

Muyaroah, S., \& Fajartia, M. (2017). Pengembangan Media Pembelajaran Berbasis Android dengan menggunakan Aplikasi Adobe Flash CS 6 pada Mata Pelajaran Biologi Abstrak, 6(2301), 79-83. 